\title{
Nutritional status of cancer patients in chemotherapy; dietary intake, nitrogen balance and screening
}

\author{
Olof Gudny Geirsdottir* and Inga Thorsdottir
}

Unit for Nutrition Research, National University Hospital, Reykjavik, Iceland

Abstract

Objective: To evaluate a short screening sheet (SSM) for malnutrition and to investigate the nutritional status of patients receiving chemotherapy for cancer of the lungs, colon or breast at an outpatient clinic.

Design: Full nutritional assessment was conducted to define malnutrition and validate the SSM. Additionally, weight change from earlier healthy weight was evaluated, and calculations for intake of energy-giving nutrients (three-day-weighed food records) and protein balance were performed. After the evaluation study, the SSM was tested in clinical routine and data collected about patients' need for nutritional counseling.

Subjects: Patients at the outpatient clinic of the Department of Oncology at Landspitali-University Hospital ( $n=30$ with lung-, colon- or breast cancer in the study population, $n=93$ with all cancer type in clinical routine screening).

Results: Malnutrition was defined by full nutritional assessment in 20\% of the participating patients and SSM had high sensitivity and specificity. Declining nutritional status of the patients was seen as a negative nitrogen balance and unintentional weight loss from healthy weight, but not as total energy intake, recent weight loss or underweight. The test of SSM in clinical routine showed that $40 \%$ were malnourished. According to the patients, $80 \%$ needed nutritional counseling but only $17 \%$ had such counseling.

Conclusion: Screening (SSM) for malnutrition in cancer patients is a valid simple approach to define cancer patients for nutritional care. More patients regard themselves in need for nutritional counseling than the number of patients really achieving any.

Keywords: screening malnutrition; nutritional counseling; malnutrition; protein balance; protein loss; weight loss

Received: 15 July 2008; Revised: 2 I October 2008; Accepted: I2 November 2008; Published: 12 December 2008

$\mathrm{M}$ alnutrition in cancer increases the risk of infections and the cost of healthcare. It decreases the patients' quality of life (QoL), affecting both responses to anticancer treatment and overall survival (1-5).

Fundamental to tackling the malnutrition problem is to detect it. Nutritional screening should provide the opportunity to identify malnutrition or individuals at high nutritional risk at an early stage of medical care in a non-invasive, inexpensive and feasible way. Routine screening of patients to identify risk of malnutrition has been recommended by many national, international and specialist organizations $(6,7)$.

The lungs, colon and breasts are leading sites of cancer in westernized countries (8). These cancers are commonly treated with chemotherapy, which often has adverse effect on the nutritional status of the affected patient. More knowledge is needed about the nutritional status and diet of patients in chemotherapy for lung, colon and breast cancer.

The aim of the present study was to evaluate a simple screening tool for malnutrition (short screening sheet, SSM) of patients in chemotherapy for cancer of the lungs, colon and breasts at an outpatient clinic using full nutritional assessment as the reference. Dietary intake and nitrogen balance were also investigated in the patient group. Finally, the screening tool was tested in cancer patients in chemotherapy in a clinical routine.

\section{Methods}

\section{Study sample}

The participants $(n=30)$ constituted $38 \%$ of all patients in chemotherapy at the Department of Oncology at Landspitali-University Hospital with breast, colon or lung cancer. The mean age was 55 years (range 29-72 
years) (Table 1). All patients with breast, colon or lung cancer $(n=79)$ were invited to participate in the study during the data collection. The most common explanation for not participating was that 'people were too sick' or 'the burden of the study was too heavy'.

All patients were asked about their usual physical activity. They were all sedentary or had a low physical activity level (PAL). The mean body mass index (BMI) was $27 \pm 6 \mathrm{~kg} / \mathrm{m}^{2}$ and 15 were overweight or obese patients with BMI over 25, two were underweight with BMI below 20.

The study was approved by the Local Ethical Committee at Landspitali-University Hospital in Reykjavik, Iceland.

\section{Nutritional assessment}

Full nutritional assessment

A full nutritional assessment was conducted as described earlier (9-11) by measurements of BMI, triceps skinfold thickness (TST), mid-arm muscle circumference (MAMC), serum albumin (alb), serum prealbumin (palb), total lymphocyte count (TLC) and unintentional weight loss of more than $5 \%$ within the preceding month or $10 \%$ or more within the previous 6 months (10).

Table 1. Characteristics of the cancer patients (mean \pm SD)

\begin{tabular}{|c|c|c|c|}
\hline & Male $(n=9)$ & Female $(n=2 \mathrm{I})$ & All $(n=3)$ \\
\hline Age $(y)$ & $60 \pm 11$ & $53 \pm 12$ & $55 \pm 12$ \\
\hline Weight (kg) & $89 \pm 26$ & $72 \pm 15$ & $77 \pm 20$ \\
\hline Height (cm) & $179 \pm 7$ & $167 \pm 6$ & $170 \pm 9$ \\
\hline BMI & $28 \pm 8$ & $26 \pm 5$ & $27 \pm 6$ \\
\hline BMR (kcal/d, calculated) & $1639 \pm 162$ & $1331 \pm 102$ & $1423 \pm 187$ \\
\hline Breast cancer $(n=19)$ & & Female $(n=19)$ & \\
\hline Age & & $53 \pm 12$ & \\
\hline Weight & & $73 \pm 15$ & \\
\hline Height & & $168 \pm 5$ & \\
\hline BMI & & $26 \pm 5$ & \\
\hline BMR & & $1335 \pm 102$ & \\
\hline Colon cancer $(n=8)$ & Male $(n=7)$ & Female $(n=1)$ & All $(n=3)$ \\
\hline Age & $61 \pm 10$ & 58 & $61 \pm 9$ \\
\hline Weight & $91 \pm 30$ & 57 & $87 \pm 30$ \\
\hline Height & $180 \pm 7$ & 150 & $176 \pm 13$ \\
\hline BMI & $28 \pm 9$ & 25 & $28 \pm 8$ \\
\hline BMR & $1579 \pm 158$ & 1128 & $1522 \pm 210$ \\
\hline Lung cancer $(n=3)$ & Male $(n=2)$ & Female $(n=1)$ & All $(n=3)$ \\
\hline Age & $57 \pm 17$ & 49 & $54 \pm 13$ \\
\hline Weight & $79 \pm 3$ & 70 & $76 \pm 5$ \\
\hline Height & $174 \pm 8$ & 160 & $169 \pm 10$ \\
\hline BMI & $26 \pm 3$ & 27 & $27 \pm 2$ \\
\hline BMR & $1511 \pm 289$ & 1265 & $1428 \pm 249$ \\
\hline
\end{tabular}

Malnutrition was defined as present when three or more of these seven parameters were subnormal. In addition, weight change from patients' self-reported earlier healthy weight was evaluated.

Biochemical measures and reference values were obtained from the laboratory at Landspitali-University Hospital. Values for TST and MAMC (Table 2) were compared with normal values from the National Health and Nutrition Examination Survey (NHANES) as described previously (10).

Nutritional screening

The SSM sheet (Fig. 1, (10)) is made up of seven questions covering BMI, weight loss, anorexia, surgery and other variables that may influence nutritional status. No measurements other than weight and height were needed for answering the questions. Each question gave a score according to the answers. The criterion set for malnutrition was a total score of five or more points.

Food record

Three-day-weighed food records were completed for all patients $(n=30)$ participating in the study and assumed to be sufficient for estimating energy and protein intake on an individual basis (12). Patients did the food record between chemotherapies when they were feeling better, usually starting on fourth or fifth day after chemotherapy.

The intake of macronutrients, energy, protein, fat, and carbohydrates was analyzed for each patient using KOSTPLAN for Windows, version 1.0 (AIVO AB, Stockholm, 1996).

Table 2. Mean value $\pm \mathrm{SD}$ and reference value of nutritional parameters used for the full nutritional assessment of cancer patients $(n=30)$

\begin{tabular}{lcccc}
\hline Parameters & $\begin{array}{c}\text { Male } \\
(n=9)\end{array}$ & $\begin{array}{c}\text { Female } \\
(n=2 \mathrm{I})\end{array}$ & $\begin{array}{c}\text { Mean } \\
(n=30)\end{array}$ & Reference \\
\hline Alb $(\mathrm{g} / \mathrm{L})$ & $4 \mathrm{I} \pm \mathrm{I})$ & $36 \pm 3$ & $38 \pm 10$ & $38-5 \mathrm{I}$ \\
Palb $(\mathrm{mg} / \mathrm{L})$ & $304 \pm 67$ & $268 \pm 49$ & $279 \pm 56$ & $180-450$ \\
TLC $\left(\times 10^{9}\right)$ & $1.6 \pm 0.9$ & $1 . I \pm 0.6$ & $1.3 \pm 0.8$ & $>1.8$ \\
BMI $\left(\mathrm{kg} / \mathrm{m}^{2}\right)$ & $28 \pm 8$ & $26 \pm 5$ & $27 \pm 6$ & $>20$ \\
TST $(\mathrm{mm})$ & $7 \pm 2$ & $16 \pm 5$ & $13 \pm 6$ & $>5 \%$ *** \\
MAMC $(\mathrm{cm})$ & $33 \pm 4$ & $32 \pm 5$ & $32 \pm 5$ & $>5 \%$ ** \\
MAMA $\left(\mathrm{cm}{ }^{2}\right)$ & $85 \pm 25$ & $83 \pm 26$ & $84 \pm 25$ & $>5 \%$ ** \\
UWL $(\mathrm{kg})$ & $-\mathrm{I} \pm 8^{*}$ & $2 \pm 8^{*}$ & $\mathrm{I} \pm 8^{*}$ & $<5 \%$ \\
\hline
\end{tabular}

Alb =albumin; Palb = prealbumin; TLC =total lymphocyte count $\mathrm{BMI}=$ body mass index; TST $=$ triceps skinfold thickness; MAMA = mid-arm muscle area; $M A M C=$ mid-arm muscle circumference; $\mathrm{UWL}=$ unintentional weight loss previous month.

*Mean weight loss $(-)$ or weight gain $(+)$.

**NHANES (I97I-1974). 


\section{NATIONAL UNIVERSITY HOSPITAL Department of Clinical Nutrition}

\section{SCREENING FOR MALNUTRITION}

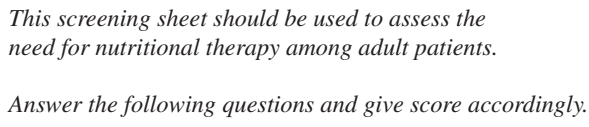

2. Recent unintentional weight loss?

If yes, how much?

In what time period?<smiles>C=[As]</smiles><smiles>[13CH3]C1=CCC1</smiles>

3. Age over 65 years?

\section{PATIENT'S I.D.}

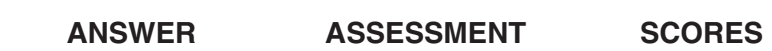

BMI: Kg/m²
$\square$ Yes $\square_{\text {No }}$
$\square \quad$ Doesn't
know
Weight loss \%
$\square$
$\square$ Yes $\square_{\text {No }}$

\begin{tabular}{|ll}
$>20$ & 0 scores \\
$18-20:$ & 2 scores \\
$<18:$ & 4 scores
\end{tabular}

Unintentional weight loss:

$>5 \%$ past month or

$>10 \%$ previous 6 mo. 4 scores

$5-10 \%$ " 1-6 mo. 2 scores

Doesn't know 2 scores

Other 0 scores

$\begin{array}{ll}\text { Question } 3 \text { to 8: } & \\ \text { Yes: } & 1 \text { scores } \\ \text { No: } & 0 \text { scores }\end{array}$

No:

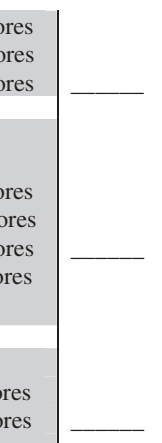

SCORES

4. Problems last weeks or months?

A. Vomiting lasting more than 3 days ?

B. Daily diarrhoea

(more than 3 liquid stools per day)?

C. Continuous loss of appetite or nausea?

D. Difficulty in chewing or swallowing?

5. Hospitalised for 5 days or more during previous 2 months? $\square$ Yes

6. Major surgery in the past month?

If yes, list type

$\square$ Yes $\square$ No

7. Diseases -5 points

Burn $>15 \%$

Malnutrition

Multiple trauma

$\square$ Yes $\square$ No

$\square$ Yes $\square$ No

$\square$ Yes $\square_{\text {No }}$

$\square$ Yes $\square$ No

$\square$ Yes $\square$ No

\begin{abstract}
$\square \mathrm{No}$
\end{abstract}


to perform one consecutive 24-hour urine collection, which took place on the second day of the weighed food recording.

\section{Evaluation of the SSM in clinical setting}

Data were collected for one month screening period with SSM. All cancer patient $(n=93)$ in cancer therapy at the outpatient clinic of the Department of Oncology at Landspitali-University Hospital were screened. None of the 30 patients participating in the study to evaluate the screening tool for malnutrition in cancer patients were included. The screening included 50 women and 43 men, age $58 \pm 16$ years (mean \pm standard deviation, SD) range 22-96 years. In addition to the nutritional screening, the patients were asked if they needed nutritional counseling and if they had had any nutritional counseling before.

\section{Statistical analysis}

Results are presented as mean \pm SD. Data were analyzed using the Statistical Package for the Social Sciences (version 9.0 for Windows, 1999, SPSS, Chicago, IL) for descriptive statistics to ascertain how many patients had below-reference values on the different parameters as described earlier (10). Sensitivity, specificity, and predictive values were calculated to evaluate single parameters and the screening sheet in comparison to full nutritional assessment (18).

\section{Results}

\section{Full nutritional assessment}

According to the full nutritional assessment, six of the 30 $(20 \%)$ cancer patients in chemotherapy were diagnosed as malnourished. No patient showed subnormal serum prealbumin or MAMC values (Table 2). BMI was subnormal in two of the six malnourished patients, and four of six patients with subnormal TST were malnour- ished. Unintentional weight change ranged from a $22 \%$ weight loss to $32 \%$ weight gain compared with recorded weight at first visit to the oncology clinic. The unintentional weight change was not significant due to this wide range of patient's weight changes. However, if the patients' self-reported earlier usual healthy weight was the reference for unintentional weight loss, all of the malnourished patients had lost considerable weight, mean $7.9 \pm 3 \mathrm{~kg}($ mean $\pm \mathrm{SD})$.

\section{Screening sheet}

The SSM identified seven of 30 patients $(23 \%)$ as malnourished. The evaluation of SSM and the seven single nutritional parameters used in the full nutritional assessment to indicate malnutrition among cancer patients is shown in Table 3.

The SSM had a sensitivity of 0.83 and the specificity was 0.96. Few individual nutritional parameters had sensitivity above 0.5 , and no parameter reached the quality of the SSM. If the patients' earlier self-reported usual healthy weight was used as the reference for unintentional weight loss, this was the single best parameter with high sensitivity (0.87) and specificity (0.88), and $13 \%$ misclassification.

\section{Food intake}

The energy intake was $2032 \pm 500 \mathrm{kcal} / \mathrm{d}$ (mean \pm SD), range 1100-3200. Overweight cancer patients reported a lower energy intake of $1837 \pm 108 \mathrm{kcal} / \mathrm{d}($ mean \pm SD) than those not overweight $2227 \pm 132 \mathrm{kcal} / \mathrm{d}(p=0.03)$. Malnourished cancer patients had higher energy intake per $\mathrm{kg}$ body weight than those who were not malnourished $(p=0.01)$, but total energy intake did not differ. Energy and nutrient intakes are summarized in Table 4.

The average calculated basal energy expenditure was $1456 \pm 169 \mathrm{kcal} / 24$ hour. When energy intake was expressed as $\mathrm{kcal} / \mathrm{kg}$ of actual weight, the average intake

Table 3. Statistical evaluation of indicators for malnutrition in cancer patients

\begin{tabular}{|c|c|c|c|c|c|c|c|c|}
\hline & SSM & TST & MAMC & BMI & $\begin{array}{c}5-10 \% \\
\text { weight loss }\end{array}$ & Alb & Palb & TLC \\
\hline Sensitivity & 0.83 & 0.67 & 0 & 0.17 & 0.17 & 1 & 0 & I \\
\hline Specificity & 0.96 & 0.88 & I & I & 0.96 & 0.37 & 1 & 0.25 \\
\hline Positive predictive value & 0.83 & 0.57 & $*$ & I & 0.50 & 0.29 & $*$ & 0.25 \\
\hline Negative predictive value & 0.96 & 0.92 & 0.80 & 0.83 & 0.82 & 1 & 0.8 & 1 \\
\hline False positive & 1 & 3 & 0 & 0 & I & 15 & 0 & 18 \\
\hline False negative & I & 2 & 6 & 5 & 5 & 0 & 6 & 0 \\
\hline Misclassification rate & 6.7 & 16.7 & 20.0 & 16.7 & 20.0 & 50.0 & 20.0 & 60.0 \\
\hline
\end{tabular}

SSM = screening sheet; TST = triceps skinfold thickness; MAMC = mid-arm muscle circumference; $\mathrm{BMI}=$ body mass index; $5-10 \%$ unintentional weight loss in last month; alb = serum albumin; palb =serum prealbumin; TLC = total lymphocyte count.

*No patient below reference value for this parameter. 
Table 4. Daily intake of energy and energy-giving nutrients in cancer patients $(n=30)$, estimated from three-day-weighed food records (mean $\pm \mathrm{SD}$ ), and Nordic Nutrition Recommendations for energy-giving nutrients (15)

\begin{tabular}{lcccc}
\hline & Male $(n=9)$ & Female $(n=21)$ & Total $(n=30)$ & NNR \\
\hline Energy (kcal) & $2327 \pm 448$ & $1906 \pm 475$ & $1905 \pm 500$ & \\
Protein (g/d) & $101 \pm 19$ & $73 \pm 19$ & $76 \pm 22$ & \\
Protein (\%E) & $17 \pm 3$ & $16 \pm 2$ & $16 \pm 3$ & $10-15$ \\
Fat (g/d) & $87 \pm 23$ & $75 \pm 23$ & $73 \pm 23$ & \\
Fat (\%E) & $33 \pm 5$ & $35 \pm 6$ & $34 \pm 6$ & $<30$ \\
CHO (g/d) & $270 \pm 45$ & $224 \pm 69$ & $223 \pm 66$ & \\
CHO (\%E) & $47 \pm 5$ & $47 \pm 7$ & $47 \pm 7$ & $55-60$ \\
\hline
\end{tabular}

$\mathrm{CHO}=$ carbohydrate.

was $28( \pm 9) \mathrm{kcal} / \mathrm{kg}$ of body weight and $29( \pm 8) \mathrm{kcal} / \mathrm{kg}$ of ideal body weight for obese patients. Energy intake averaged $144 \%$ of calculated basal energy expenditure, using ideal body weight for obese patients.

\section{Nitrogen balance}

Dietary protein intake estimated from weighed food records was $1.1 \pm 0.3 \mathrm{~g} / \mathrm{kg}$ of ideal body weight. Nitrogen excretion including $2 \mathrm{~g} / \mathrm{d}$ estimated loss from non-urine routes exceeded nitrogen intake by $2.4 \pm 4 \mathrm{~g} \mathrm{~N} / 24$ hour and was significantly different from zero $(p=0.006)$. This negative nitrogen balance means $15.5 \pm 27.8 \mathrm{~g} /$ day protein loss. Patients $(n=17)$ putting on weight or weight stable in chemotherapy had significantly $(p=0.006)$ negative nitrogen balance.

\section{Evaluation of the SSM in clinical setting}

Nutritional screening of all cancer patients $(n=93)$ at the outpatients Department of Oncology with the SSM indicated that $41 \%$ of the patients were malnourished. According to the patients' answers to the questions about nutritional counseling, the majority $(80 \%)$ needed dietary counseling but only $17 \%$ had received such counseling earlier.

\section{Discussion}

This study showed that $20 \%$ of cancer patients in an outpatient clinic with a clinical diagnosis of breast, colon, or lung cancer were malnourished. Weight loss and malnutrition are common in patients with advanced malignant diseases that adversely influence patient survival and QoL (19-21).

Unintentional weight loss has often been reported in cancer patients (18) and regarded as a stronger variable for detection of malnutrition than BMI $(22,23)$. In the present study, general unintentional weight loss from patients' self-reported earlier usual healthy weight was found to be the best single parameter for detecting malnutrition. However, it did not reach the quality of the SSM in terms of specificity and misclassification.

A majority of the patients had serum albumin $(70 \%)$ and TLC $(80 \%)$ below the reference value. Previous studies have implicated that pro-inflammatory tumor derived mechanisms influence the hepatic acute phase protein response, which makes measurements of serum albumin and immunocompetence such as TLC of limited value. Serum albumin is the most widely used clinical index of nutrition, but because of its long half-life and affection by stress and illness (24) it can be regarded as a poor parameter of nutritional status. Also many cancer therapy drugs cause low TLC and serum albumin (25). This underlines that nutritional status cannot be evaluated from one or two single parameters and supports the need for several measurements as used in the present study.

A large number of screening tools have been reported and promoted in various settings. The main advantage of the present SSM as a screening tool is that it is a very simple tool, with only seven simple questions, and only weight and height have to be measured. The SSM have been validated with high sensitivity and are used in routine clinical screening in other departments at Landspitali-University Hospital (9-11). Sensitivity in nutritional screening is very important for realization of the goal of finding malnourished patients, and specificity for preventing well-nourished patients being classified as malnourished. The sensitivity of the SSM was higher in the present study of cancer patients than found in earlier studies for other patient groups $(9,10,26)$.

Energy and nutrient intake was within normal range. However, our results show a significant negative nitrogen balance and indicating that the majority $(n=21)$ of patients were losing protein. The tendency of muscle loss in cancer has been reviewed by others (27) with the conclusion that many factors including patient's age, physical activity and cancer related protein metabolism influence the skeletal muscle. Also drugs commonly used in chemotherapy are known to cause negative nitrogen balance (25). Aslani et al. (28) conclude that weight gain observed during adjuvant chemotherapy for breast carcinoma is primarily due to an increase in fat and total body water. Negative nitrogen balance shows that a majority of these cancer patients have aggravated nutritional status even though some of the patients are putting on weight. Therefore, the present study supports the assertion that malnutrition and negative nitrogen balance in cancer patients can be substantial without abnormal weight loss, energy intake or BMI.

The study has limitations due to the high drop out rate and a small number of patients who were investigated. Only patients who considered that they could manage the burden of the study participated. Therefore, it can be speculated that the nutritional status is worse among 
patients with more severe types of cancer or those with more severe side effects from the chemotherapy.

Data from one month screening with SSM indicated that $41 \%$ of all cancer patients in chemotherapy were malnourished or in nutritional risk. The majority of the screened patients are regarded themselves in need of nutritional counseling, but only few had received nutritional counseling. This study supports other reports that nutritional issues are underestimated in diagnostic and therapeutic procedures $(1,19,20)$. It has been concluded from the results of other studies that early nutritional support is necessary to improve patient's nutrient status and controlling complications related to food intake which influence patients' QoL (29). Nutritional interventions can affect a cancer patient's outcome. Nutrition is more than just food; it is an essential part of clinical care that can be improved.

\section{Conflict of interest and funding}

The Authors have received funding from Fund for Research Training and Graduate Education; The Icelandic Research Council and the Research Fund of the University of Iceland.

\section{References}

1. Nitenberg G, Raynard B. Nutritional support of the cancer patient: issues and dilemmas. Crit Rev Oncol Hematol 2000; 34: 137-68.

2. Isenring E, Bauer J, Capra S. The scored Patient-generated Subjectivve Global Assessment (PG-SGA) and its association with quality of life in ambulatory patients receiving radiotherapy. Eur J Clin Nutr 2003; 57: 305-9.

3. Capra S, Ferguson M, Ried K. Cancer: impact of nutrition intervention outcome - nutrition issues for patients. Nutrition 2001; 17: 769-72.

4. Tian J, Chen JS. Nutritional status and quality of life of the gastric cancer patients in Changle County of China. World J Gastroenterol 2005; 11: 1582-6.

5. Ravasco P, Monteiro-Grillo I, Vidal PM, Camilo ME. Dietary counseling improves patient outcomes: a prospective, randomized, controlled trial in colorectal cancer patients undergoing radiotherapy. J Clin Oncol 2005; 23: 1431-8.

6. Elia M, Stratton R. On the ESPEN guidelines for nutritional screening 2002. Clin Nutr 2004; 23: 131-2.

7. Kondrup J, Allison SP, Elia M, Vellas B, Plauth M, Educational and Clinical Practice Committee, European Society of Parenteral and Enteral Nutrition (ESPEN). ESPEN guidelines for nutrition screening 2002. Clin Nutr 2003; 22: 415-21.

8. Colditz GA. Hormones and breast cancer: evidence and implications for consideration of risks and benefits of hormone replacement therapy. J Womens Health 1999; 8: 347-57.

9. Thorsdottir I, Eriksen B, Eysteinsdottir S. Nutritional status at submission for dietetic services and screening for malnutrition at admission to hospital. Clin Nutr 1999; 18: 15-21.

10. Thorsdottir I, Gunnarsdottir I, Eriksen B. Screening method evaluated by nutritional status measurements can be used to detect malnourishment in chronic obstructive pulmonary disease. J Am Diet Assoc 2001; 101: 648-54.

11. Thorsdottir I, Jonsson PV, Asgeirsdottir AE, Hjaltadottir I, Bjornsson S, Ramel A. Fast and simple screening for nutritional status in hospitalized, elderly people. J Hum Nutr Diet 2005; 18: $53-60$.

12. Bingham SA, Nelson M, Paul AA, Haraldsdottir J, Lö ken EB, van Starven WA. Methods for data collection at an individual level. In: Cameron ME \& van Starveren WA, eds., Manual on methodology for food consumption studies. New York: Oxford University Press; 1988; 53-106.

13. Van Way CW. Variability of Harris-Benedict equation in recently published textbooks. JPEN 1992; 16: 566-8.

14. Hamwi GJ. Changing dietary concepts. In: Danowski TS, ed., Diabetes mellitus: diagnosis and treatment, vol. 1. New York: ADA; 1964. p. 73-8.

15. Barak N, Wall-Alonso E, Sitrin MD. Evaluation of stress factors and body weight adjustments currently used to estimate energy expenditure in hospitalized patients. JPEN 2002; 26: 231-8.

16. Hill GL. Disorder of nutrition and metabolism in clinical surgery. Churchill Livingstone: Edinburgh; 1992.

17. Johnston-Miller S. The nitrogen balance revised. Hosp Pharm 1990; 25: 61-6.

18. Watson RA, Tang DB. The predictive value of prostatic acid phosphatase as a screening test for prostatic cancer. N Engl J Med 1980; 303: 497-9.

19. Delmore G. Assessment of nutritional status in cancer patients: widely neglected? Support Care Cancer 1997; 5: 376-80.

20. Laviano A, Meguid MM. Nutritional issues in cancer management. Nutrition 1996; 12: 358-71.

21. Nourissat A, Vasson MP, Merrouche Y, Bouteloup C, Goutte $\mathrm{M}$, Mille $\mathrm{D}$, et al. Relationship between nutritional status and quality of life in patients with cancer. Eur J Cancer 2008; 44: 1238-42.

22. Lipkin EW, Bell S. Assessment of nutritional status. The clinician's perspective. Clin Lab Med 1993; 13: 329-52.

23. Orr JW, Jr, Shingleton HM. Importance of nutritional assessment and support in surgical and cancer patients. J Reprod Med 1984; 29: 635-50.

24. Wong PW, Enriques AE, Barrera R. Nutritional support in critically ill patients with cancer. Oncol Crit Care 2001; 17: 743 67.

25. Forse RA, Rompre C, Crosilla P, O-Tuitt D, Rhode B, Shizgal HM. Reliability of the total lymphocyte count as a parameter of nutrition. Can J Surg 1985; 28: 216-9.

26. Bauer J, Capra S, Ferguson M. Use of the scored PatientGenerated Subjective Global Assessment (PG-SGA) as a nutrition assessment tool in patients with cancer. Eur J Clin Nutr 2002; 56: 779-85.

27. Skipworth RJE, Stewart GD, Dejong CHC, Preston T, Fearon $\mathrm{KCH}$. Pathopysiology of cancer cachexia: Much more than host-tumor interaction? Clin Nutr 2007; 26: 667-76.

28. Aslani A, Smith RC, Allen BJ, Pavlakis N, Levi JA. Changes in body composition during breast cancer chemotherapy with the CMF-regimen. Breast Cancer Res Treat 1999; 57: 285-90.

29. Ravasco P, Monteiro Grillo I, Camilo M. Cancer wasting and quality of life react to early individualized nutritional counselling! Clin Nutr 2007; 26: 7-15.

\footnotetext{
*Olof Gudny Geirsdottir

Unit for Nutrition Research

National University Hospital

P.O. Box 10

IS-I2I Reykjavik, Iceland

Tel: + 354543841 I

Fax: +3545434824

E-mail: olofgg@landspitali.is
} 